\title{
Bitcoin ve Türevi Varlıkların Muhasebeleştirilmesine İlişkin Bir Değerlendirme
}

\section{An Evaluation on The Recognition of Bitcoin and Derivative Assets in Accounting}

\author{
Dr. Öğr. Üyesi Hasan GÜL (iD) 1
}

\begin{abstract}
$\ddot{O} z$
Blok zincir (Blockchain) teknolojisinin bir ürünü olarak ortaya çıkan Bitcoin ve türevi kripto paralar son on yılın en önemli ekonomik yeniliğidir. Bitcoin, eşler arası veri paylaşım ağını (Peer-to-Peer) temel alan, merkezi bir otorite tarafından kontrol edilmeyen (decentralized), kamuya açık hesap kaydı tutma özelliğine sahip (PublicLedger), temelde online ödeme yapmayı sağlayan sanal bir para birimidir. Bitcoin, kripto paraların ekonomik olarak tanınmasında temel teşkil etmiştir. Bununla birlikte günümüzde genel veya özel fonksiyonlu pek çok Bitcoin türevi (Altcoin) kripto para birimi geliştirilmiştir. Kripto paralar her geçen gün daha fazla sayıda ticari işlemde kullanılmaya başlanmıştır. Kripto paralarla yapılan işlemlerin nasıl muhasebeleştirileceğine ilişkin henüz belirgin bir düzenleme bulunmaması farklı yaklaşımları da beraberinde getirmektedir. Bu çalışmanın amacı, mevcut yaklaşımlar ışı̆̆ında kripto paraların nasıl muhasebeleştirilebileceğini tartışmaktır.
\end{abstract}

Anahtar Kelimeler: Kripto paralar, Bitcoin, altcoin, blok zincir, muhasebe

Makale Türü: Derleme

\begin{abstract}
Bitcoin and derivative cryptocurrencies emerging as a product of blockchain technology are the most important economic innovation of the last decade. Bitcoin is a virtual and decentralized currency based on peer-to-peer networks, which has the feature of keeping records open to the public (Public Ledger) and allows making online payments. Bitcoin is the basis for the economic recognition of cryptographic money. In addition, many Bitcoin derivative cryptocurrencies (Altcoin) with general or special functions have been developed in the commercial process. Cryptocurrencies are used increasingly in commercial transactions. The lack of a specific regulation on how to make journal entry for transactions with cryptocurrencies brings different approaches. The purpose of this paper is to discuss how cryptocurrencies can be make journal entry in the light of current approaches.
\end{abstract}

Keywords: Cryptocurrencies, Bitcoin, altcoin, blockchain, accounting

Paper Type: Review

\footnotetext{
${ }^{1}$ Çanakkale Onsekiz Mart Üniversitesi, Ezine Meslek Yüksekokulu, hasangul17@gmail.com.
} 


\section{Giriş}

Bütün sistemler gibi ekonomi de zamanın gereklerine uygun olarak değişip dönüşmektedir. İnsan toplulukları arasındaki ilk ticari faaliyetten bugüne ekonomik faaliyetler ve bu faaliyetler için kullanılan enstrümanlar değişmiştir. Ticari faaliyetlerin konusu değişip genişledikçe ödeme sistemleri de ona uygun biçimde farklılaşmıştır. Özetle, takas, mal para, itibari para ve dijital para bu değişim sürecinde kullanılan ödeme sistemleri olarak karşımıza çıkmaktadırlar.

Dijital para ekosisteminin ${ }^{2}$ en yeni parçasını kripto paralar (cryptocurrency) oluşturmaktadır. Kripto para, kriptografi ${ }^{3}$ yöntemleriyle üretilen ve kullanılan sanal nitelikte dijital bir para türüdür. Bu paralar matematiksel formüller kullanılarak bilgisayar ağları üzerinde üretilmektedir. Günümüzde bine yakın kripto para birimi bulunmaktadır. Fakat bunların en önemlisi ve sistemin temelini oluşturan kripto para birimi Bitcoin'dir (Kısaltması BTC). Bitcoin 2009 yılında üretilmiş ilk kripto paradır ve o günden beri genişleyen oranda ekonomik faaliyetlere konu olmaktadır ${ }^{4}$.

Türkiye Finansal Raporlama Standartları (TFRS) finansal raporlamaya ilişkin kavramsal çerçevede "geçmişte olan işlemlerin sonucunda ortaya çıkan ve halihazırda işletmenin kontrolünde olan ve gelecekte işletmeye ekonomik fayda sağlaması beklenen" değerler varlık olarak tanımlanmıştır. Yine, "Bir kalemin varlık, borç veya özkaynaklar tanımı kapsamında yer alıp almadığını değerlendirirken sadece hukuki biçime değil, kalemin özüne ve ekonomik anlamına bakılır" denilmektedir. Ayrıca, "bazı varlıkların fiziken var olmaları şart değildir. Eğer gelecekte oluşacak ekonomik değer taşıyorlarsa ve işletme tarafindan kontrol ediliyorlarsa, örneğin, patentler ve telif haklarında olduğu gibi varlık olarak kabul edilir" ifadeleri geçmektedir (Kamu Gözetimi Muhasebe ve Denetim Standartları Kurumu, 2018). Kripto paralar, ekonomik işlemlerle elde edilen, kripto para cüzdanlarında saklanabilen, değiş tokuşa konu olabilen ekonomik ürünlerdir.

Basit bir ifadeyle kripto para sahibi olmak -arada bir banka veya finans kurumunun bulunmadığı- mevduat hesabı sahibi olmaya benzetilebilir. Dolayısıyla, kripto paralar özü itibariyle bir varlık çeşididir ve ticari işlemlere konu olduklarından muhasebeleştirilmeleri gerekmektedir. Fakat henüz kripto paralarla yapılan işlemlerin nasıl muhasebeleştirileceğine ilişkin belirgin bir düzenleme bulunmamaktadır. Kripto paralara ilişkin yasal bir düzenlemenin yapılmamış olması ve diğer varlık unsurlarından farklılık göstermesi onların nasıl muhasebeleştirileceğine ilişkin tartışmaları da beraberinde getirmektedir.

\section{Bitcoin ve Altcoin ${ }^{5}$ (Kripto Paralar) ${ }^{6}$}

Bitcoin, ilk üretimi $2009^{7}$ yılında yapılmış sanal nitelikte dijital bir para (sanal para) birimidir. Daha teknik bir tanımlamayla Bitcoin, merkezi bir otorite tarafından kontrol

\footnotetext{
${ }^{2}$ Dijital para ekosistemi, elektronik ortamda üretilen, saklanan ve transferi gerçekleştirilen her türlü parayı ifade etmektedir. Bu anlamıyla elektronik para sistemleri (debit kartlar, akıllı kartlar ve elektronik nakit) ve sanal para sistemleri (Linden Doları, Kripto paralar) dijital para ekosistemini oluşturmaktadır.

${ }^{3}$ Kriptografi, verilerin açık halden kapalı yani gizli hale getirilmesi ișlemidir. Kriptografi, bilginin olduğu șekilden daha farklı bir formda saklanması veya iletilmesiyle ilgilenmektedir. Kriptografinin temel amacı verinin (bilginin) gizliliğini sağlamaktır (Coşkun ve Ülker, 2013, s. 32-33). Kripto para sisteminde kriptografinin kullanım amacı para işlemlerinin gizliliğini, bütünlüğünü, güvenliğini sağlamak ve yeni paraların üretilmesini kontrol etmektir.

${ }^{4} 2013$ Haziran ayı içerisinde yaklaşık 100 dolar fiyatı ve 1,2 Milyar dolar piyasa değeri olan Bitcoin, 2017 Şubat ayı içerisinde 20.000 dolar fiyat seviyesine ve 330 Milyar dolar piyasa değerine yaklaşmıştır (https://coinmarketcap.com/ currencies/bitcoin/\#charts Erişim tarihi: 11.09.2018). Bununla birlikte Bitcoin 2011 yılında 2 dolar civarında fiyatlanırken, bu çalışmanın yürütüldüğ̈̈ 2018 Eylül ayı içerisinde 6.500 Dolar civarında işlem görüyordu. Günümüzde aralarında büyük şirketlerin de olduğu pek çok işletme Bitcoin'i bir ödeme aracı olarak kabul etmektedir. Microsoft, Reddit, Virgin Galactic, Overstock.com, KFC Kanada, Wikipedia bu kapsamda sayılabilecek büyük işletmelerden bazılarıdır (Chokun, 2018).

5 Altcoin kavramı "alternatif coin" ifadesinin kısaltması olarak kullanılmaktadır. Aternatif coin, Bitcoin dıșındaki diğer kripto paraların genel ismidir. Bitcoin dışındaki tüm kripto paralar altcoindir.

${ }^{6} \mathrm{Bu}$ çalış̧mada Bitcoin ve altcoinler ifadesi yerine zaman zaman kripto paralar ifadesi kullanımı tercih edilmiştir

72009 yllında yazar ismi Satoshi Nakamoto (kim ya da kimler olduğu halen bilinmiyor) olan"Bitcoin: A Peer-to-Peer Electronic Cash System" başlıklı bir makale yayınlandı. Nakamoto bu makalede -kişi ya da kurumlara- güven yerine kriptografik ispata dayanan bir ödeme sistemi önerdi (Nakamoto, 2008). Bu sistem sayesinde bir aracıya (banka vb.) ihtiyaç duymadan doğrudan kişiden kişiye
} 
edilmeyen (Decentralized), eşler arası veri paylaşım ağını (Peer-to-Peer) temel alan, kamuya açık hesap kaydı tutma özelliğine sahip (PublicLedger), kriptografi yöntemleri kullanılarak üretilen ve işletilen bir sanal para ${ }^{8}$ birimidir.

Bitcoin'in temel özelliklerini şu şekilde sıralamak mümkündür:

1) Merkeziyetsizlik (Decentralized): Bitcoin ve genel olarak kripto para birimleri herhangi bir merkezi otorite tarafindan kontrol edilmemektedir. Dolayısıyla mevcut para ve maliye politikalarından bağımsız olarak kamuoyu tarafından bilinen oranda sistemin kullanıc1ları tarafından kolektif olarak üretilmektedir (Gültekin, 2017, s. 97). Kripto para birimlerinde arz olacak para miktarı ve halihazırda ne kadar arz edildiği sistem tarafından şeffaf şekilde paylaşılmaktadır. Örneğin, Bitcoin en fazla 21 milyon adet üretilecektir ve şu ana kadar 17 milyonun biraz üzerinde üretilmiştir (https://coinmarketcap.com/currencies/bitcoin/Erişim tarihi: 27.08.2018).

2) Eşler arası veri paylaşımı (Peer to Peer veya P2P): Bir ağda birbirine "eş" bilgisayarların bir sunucuya ihtiyaç duymadan veri paylaşımı yapmasını sağlayan bir dosya protokolüdür. Kripto para sisteminde eşler arasında veri paylaşımı kullanılarak bir sunucuya ihtiyaç duyulmadan para transferi yapılabilmektedir. Eşler arasında veri paylaşımında veri kolektiftir ve denetlenmez.

3) Kamuya açık hesap kaydı (PublicLedger): Bitcoin, blok zincir (Blockchain) denilen bir teknolojik alt yapıyı kullanmaktadır. Blok zincir, verilerin bloklar halinde senkronize halde ağda saklanmasını sağlayan bir teknolojidir. Blok zincir, bitcoin ağında yapılan işlemlerin kayıtlarının tutulmasını, bu kayıtların sisteme bağlı her noktaya dağıtılmasını ve her noktada aynı kayıtların bulunmasını sağlamaktadır. Bütün işlem kayıtlarına açık defter anlamında "pubicledger" denmektedir. Publicledger kripto para işlemlerini kamuya açık bir hale getirmektedir. Kripto para sisteminde yapılan tüm transfer işlemleri gözlemlenebilir; buna karşılık işlemleri yapanların kimliği gizlidir.

4) Kriptografik sistem: Kripto paraların üretilmesi, transferi ya da saklanması gibi tüm işlemler kriptografi yöntemleri kullanılarak yapılmaktadır. Kriptografi, bir bilginin istenmeyen kişilerce anlaşılmayacak hale dönüştürülmesinde kullanılan teknikler bütünüdür. Kriptografi, gizlilik, bütünlük, kimlik denetimi, inkâr edememe gibi bilginin güvenilir hale getirilmesini sağlayan matematiksel yöntemlerdir (Akleylek, Yıldırım ve Tok, 2011, s. 713).

Bitcoin'i temelde iki şekilde elde etmek mümkündür. İlk yöntem, Bitcoin takas işlemlerine aracıllk yapan kuruluşlardan (Kripto para borsaları) kabul ettikleri tedavüldeki bir para karşılı̆̆ında Bitcoin satın alınmasıdır. Örneğin Türkiye'de faaliyet gösteren kripto para borsalarından Türk Lirası karşılığında anlık değeri üzerinden Bitcoin satın alınabilmektedir.

\footnotetext{
transfer yapabilecekti. Nakamoto, makalenin yayınlanmasından bir süre sonra bahsettiği bilgisayar yazılımını da paylaştı. Bu uygulamanın kullanılmaya başlaması sonucu Bitcoin doğdu.

${ }^{8}$ Sanal paralar, bir merkez bankası ya da kamu otoritesi tarafından üretilmeyen, resmi bir para birimine bağlı olmayan ancak gerçek veya tüzel kişiler tarafindan bir değişim aracı olarak kabul edilen; elektronik olarak aktarılabilen, depolanabilen ve ticarete konu edilebilen dijital bir değer temsilidir. Diğer bir ifadeyle sanal para, geliștiricileri tarafindan üretilen ve genellikle kontrol edilen, belirli bir topluluk arasında kullanılan ve kabul edilen regüle edilmemiş (yasal bir otorite tarafından düzenlemeye tabi tutulmamış) bir dijital para tipi olarak tanımlanabilir (Fico, 2018, s. 2). Sanal paralar elektronik paranın bir çeşidini oluşturmakla birlikte aralarında ciddi farklar bulunmaktadır. Elektronik parada hesap birimi tedavüldeki para birimleriyken sanal paraların kendi para birimleri vardır. Elektronik para piyasanın tamamında kabul görürken sanal paralar belirli topluluklar içinde kabul görmektedir. Elektronik para belirli yasal düzenlemelere tabi iken sanal paraların henüz yasal bir düzenlemesi yoktur. Elektronik para yasaların izin verdiği kurumlarca ihraç edilirken sanal paralar serbestçe üretilmektedir. Elektronik paranın itibari değeri garanti altındayken sanal parada değildir. Elektronik para denetim altındayken sanal parada denetim yoktur. Elektronik parada risk operasyonelken sanal parada hem operasyonel ve hukuki hem de kredi ve tedavül kabiliyeti açısından vardır (Yüksel, 2015, s. 197). Farklı türleri bulunan ve farklı amaçlarla üretilmiş sanal para birimlerini sınıflandırmak kolay değildir. Fakat, sanal para birimlerinin reel ekonomi ile olan ilișkisi göz önüne alınarak bir sınıflama yapmak mümkündür (Koçoğlu, Çevik ve Tanrı̈ven, 2016, s. 78). Bu kapsamda Avrupa Merkez Bankası sanal para sistemleri için üçlü bir sınıflandırma önermiştir: 1) Reel ekonomiyle neredeyse hiçbir bağlantısı olmayan kapalı sanal para sistemleri; 2) Belirli bir döviz kurundan "gerçek" para birimi kullanılarak satın alınabilen ancak geri satılamayan ve diğer kullanıcılarla ticareti yapılmasına izin verilmeyen tek yönlü akışkan sanal para birimi sistemleri; 3) Birimleri (dalgalı) döviz kurlarına göre satın alınabilen ve satılabilen iki yönlü akışkan sanal para sistemleri (Avrupa Merkez Bankası, 2015, s. 6). Bitcoin ve altcoinler iki yönlü akışkan sanal para sistemleri sınıfına dahildir.
} 
Ayrıca kripto paralar kendi aralarında da takas aracı olarak da kullanılmaktadır. Örneğin bir kriptopara borsasında listelenmiş (o borsada işlem gören) altcoinlerle o borsada Bitcoin veya başka altcoin satın alınabileceği gibi, Bitcoinle de altcoinler satın alınabilir.

İkinci yöntem ise Bitcoin madenciliğidir (BTC mining). Bitcoin madenciliği, özel yazılımlar kullanılarak, ağ üzerinde yapılan finansal işlemlerin onaylanması, finansal transferlerin gerçekleşmesinin sağlanması ve hesap defterinin tutulması işlemidir. $\mathrm{Bu}$ işlem zorluğu her geçen gün artan karmaşı matematiksel problemlerin çözülmesi gerekmektedir. Böylece hem yeni Bitcoin üretimi gerçekleşmekte hem de blok zincire yeni bloklar eklenmektedir. Madencilik, yeni Bitcoin üretimi ile birlikte sitemin güvenli ve senkronize olmasını sağlamaktadır.

Günümüzde Bitcoin ve altcoinlerin ne tür varlıklar olduğunu ifade etmek için merkezi otoriteler $^{9}$ tarafından yapılmış ortak bir tanım bulunmamaktadır. Örneğin Avrupa Merkez Bankası, Bitcoin ve türevlerini sanal para sınıflandırması içine sokmakla birlikte; onları, ekonomi literatüründe tanımlandığı biçimiyle tam bir para formu olarak kabul etmemektedir. Ayrıca yasal açıdan sanal paralar, nakit ya da döviz de değillerdir ${ }^{10}$ (Avrupa Merkez Bankası, 2015, s. 4).

Kripto para sistemi geleneksel para sisteminden farklı bir anlayış ve mimari üzerine inşa edilmiştir. Aşağıdaki tabloda geleneksel paralar ile kripto paraların bazı faktörlere göre karşılaştırılması sunulmuştur.

Tablo 1. Geleneksel para ile kripto para arasındaki bazı farklar

\begin{tabular}{|lll|}
\hline & Geleneksel Para & Kripto Para \\
\hline Kontrolü & Hükümetler ve Bankalar & $\begin{array}{l}\text { Herhangi bir merkez tarafindan } \\
\text { kontrol edilmez }\end{array}$ \\
\hline Üretimi & Devlet kurumları & Bilgisayar yazılımları \\
\hline Yapıs1 & Madeni ve kâğıt & Bilgisayar kodu \\
\hline $\begin{array}{l}\text { Transfer } \\
\text { Süresi }\end{array}$ & Uzun zaman alabilir & Neredeyse anında \\
\hline Güvenlik & $\begin{array}{l}\text { Çevrimiçi (Online) işlemlerde } \\
\text { zayıf güvenlik }\end{array}$ & Çevrimiçi işlemlerde oldukça güvenli \\
\hline
\end{tabular}

Kaynak: Cryptocurrency explained, t.y..

Tablo 1'de de görüldüğü gibi kripto paralar, parayı kontrol eden organizasyon, üretiminin gerçekleştirildiği sistem, yapısı, transfer süreleri ve güvenlik boyutlarıyla geleneksel paralardan oldukça farklı özellikler göstermektedir. Günümüzde Bitcoin benzeri genel ve özel nitelikli 896 kripto para birimi bulunmaktadır (https://coinmarketcap.com/coins/views/all/ Erişim tarihi: 04.09.2018).

\section{Yöntem}

Bu çalışma bir derleme makale olarak yapılandırılmıştır. Derleme makaleler belirli bir konuda yapılmış çalışmaların sınıflandırılıp derlenmesi ve nihayetinde bir özet ve sentezin oluşturulmasıyla yapılmaktadır (Herdman, 2006, s. 2). Derleme makaleler literatürü ele alış biçimleri ile farklılaşmaktadırlar. Bu tip makalelerde ilgili konuda yapılan belli başlı yayınlar ele alınarak onların özgün yanlarına ve literatüre yaptığı katkılara değinilmektedir (Review (Derleme) Makale, 2018). Nihayetinde derleme makalelerde amacın konuya ilişkin mevcut literatüre yeni ve anlamlı bir katkı yapmak olduğu söylenebilir.

\footnotetext{
${ }^{9}$ Bitcoin'in ve türevi kripto paraların temel özeliklerinden birinin merkeziyetsizlik oluşu ironik biçimde durumla örtüşmekte ve kripto para kullanıcılarını da fazlasıyla memnun etmektedir.

${ }^{10}$ Avrupa Merkez Bankası'nın Bitcoin ve türevi ürünlere bakışının olumsuz olduğu söylenebilir. Banka, kripto paraların reel ekonomiyle olan bağının zayıf olması ve işlem hacminin düşük olması sebebiyle finansal açıdan önemli bir risk olarak görmemektedir. Buna karşılık temelde onları endişelendiren, bu sistemleri içeren ve büyük bir güven kaybına yol açan bir olayın, mevcut elektronik ödeme sistemlerine, elektronik paraya veya e-ticarette kullanılan özel ödeme çözümlerine olan güvenin zayıflamasına sebep olabilecek olmasidır.
} 
$\mathrm{Bu}$ çalışmanın da amacı, kripto paraların birer varlık olarak muhasebe bilgi sistemi içinde nasıl kayıt altına alınabileceğini tartışmaktır. Kripto paraların muhasebeleştirilmesine ilişkin literatürdeki mevcut yaklaşımlar sunulduktan sonra yeni bir değerlendirme yapılarak alanyazına katkı sağlanmaya çalışılmıştır.

\section{Kripto Paraların Muhasebeleştirilmesi}

Bitcoin ve altcoinlere ilişkin henüz yasal bir düzenlemenin (regülasyon) yapılmamış olmasi ${ }^{11}$ ve diğer varlık unsurlarından farklılık göstermesi onların nasıl muhasebeleştirileceğine iliş̧in tartışmaları da beraberinde getirmiştir. Sanal para birimleriyle ilgili başvurabilecek belirgin bir düzenleme olmaması muhasebecilere işlemleri muhasebe standartlarına uyarlamaya çalışmak dışında bir alternatif bırakmamaktadır (Harrison \& Mano, 2015, s. 112).

Türkiye'de ödeme ve menkul kıymet mutabakat sistemlerine, ödeme hizmetlerine, ödeme kuruluşlarına ve elektronik para kuruluşlarına ilişkin usul ve esasların belirlendiği "Ödeme ve Menkul Kıymet Mutabakat Sistemleri, Ödeme Hizmetleri ve Elektronik Para Kuruluşları Hakkında Kanun'da" kripto paraları kapsayacak bir hüküm bulunmamaktadır. Ayrıca Bankacılık Düzenleme ve Denetleme Kurumu (BDDK) tarafindan 25 Kasım 2013 tarihinde yapılan basın açıklamasında "Herhangi bir resmi ya da özel kuruluş tarafından ihraç edilmeyen ve karş1lı̆̆ için güvence verilmeyen bir sanal para birimi olarak bilinen Bitcoin, mevcut yapısı ve işleyişi itibarıyla Kanun kapsamında elektronik para olarak değerlendirilmemekte, bu nedenle de söz konusu Kanun çerçevesinde gözetim ve denetimi mümkün görülmemektedir" ifadesi yer bulmuştur. Dolayısıyla kripto paraların ne tür bir varlık olduğu ve nasıl muhasebeleştirileceğine ilişkin bir düzenlemenin olmayışı literatürde farklı yaklaşımların ortaya çıkmasına sebep olmuştur. Ayrıca kripto paraların farklı şekillerde elde edilebilmesi de belirsizliğe yeni boyutlar katmaktadır.

Literatürde Bitcoin ve altcoinlerin muhasebeleştirilmesinde temelde dört yaklaşım olduğu görülmektedir. Bunlar, kripto paraları (i) nakit ve nakit benzeri bir ödeme aracı olarak değerlendiren yaklaşım, (ii) menkul kıymet olarak değerlendiren yaklaşım, (iii) stok olarak değerlendiren yaklaşım, (iv) maddi olmayan duran varlık olarak değerlendiren yaklaşımlardır.

Yaklaşımların ilki, kripto paraların hazır değerler hesap grubu içerisinde izlenmesini önermektedir. İkinci yaklaşımsa kripto paraların menkul kıymet olarak ele alındığı yaklaşımdır. Üçüncü yaklaşım, kripto paraların bir emtia gibi stoklar hesap grubu içerisinde izlenmesi yönündedir. Dördüncü yaklaşım ise kripto paraların maddi olmayan duran varlıklar olarak ele alınmasını önermektedir.

\subsection{Kripto Paraların Hazır Değerler Hesap Grubu İçinde İzlenmesi}

$\mathrm{Bu}$ yaklaşımı benimseyenlerden Ateş (2016, s. 362-363), Bitcoin'in bir ödeme aracı olarak kullanılmasının onu, muhasebe açısından nakit para statüsüne soktuğu görüşünü savunmaktadır. Ateş'e (2016, s. 363), göre Bitcoin "yabancı para olarak değerlendirilmeli ve diğer yabancı paralar gibi 100 Kasa ana hesabının altında "Bitcoin kasası" şeklinde bir yardımcı hesapta kayda" alınmalıdır. Bir sanal para biriminin bilinen ve karşılaştırılabilir bir değeri varsa, ticari işlemlerde kullanılabilir. Bu döviz kuru muhasebesinin temelidir (Harrison \& Mano, 2015, s. 116).

\footnotetext{
${ }^{11}$ Mart 2018'de Arjantin'de toplanan G 20 Zirvesi'nin en önemli konularından biri kripto paralardı. Zirve öncesi G20 üye ülkelerinin mali düzenlemelerinden sorumlu olan Finansal İstikrar Kurulu (FSB), birçok ülke tarafindan dile getirilen kripto para birimlerinin düzenlenmesi çağrısını reddettiğini açıkladı. FSB, bu yeni teknolojilerin uluslararası bir koordinasyon içinde takip edilmesi gerektiğini fakat bu teknolojilerin Dünya gayri safi yurtiçi hasılanın yalnızca \% 1'ini oluşturduğunu belirtti. FSB'ye göre kripto paralar küresel finansal düzen için bir tehdit oluşturmamaktadır (Türken, 2018). Buna rağmen G20 sonrası, kripto paralara ilişkin bir yasaklamanın olmayacağı buna karşılık düzenlemelerin kaçınılmaz olduğu yönünde bir fikir birliği oluşmuştur. Temmuz ayı içerisinde üye ülkelerden regülasyonlar konusunda önerilerini sunmaları beklenmektedir (Köse, 2018).
} 
Bitcoin, gerek aktife alınırken, gerekse değerleme yapılırken geçerli (spot) kur kullanılmalıdır. Geçerli kur ise işlem gününde alındığı borsanın kuru ya da mevcut Bitcoin borsalarının ortalama kuru olabilir. Kripto paralar elden çıkarılırken ya da değerleme yapılırken oluşan fark 646 Kambiyo Kârı ve 656 Kambiyo Zararları hesaplarından uygun olanı ile izlenmelidir. Kripto paraların borsadan alınması sirasında ödenen komisyonlar da 653 Komisyon Giderleri Hesabında takip edilmelidir (Ateş, 2016, s. 363).

Dizkırıcı ve Gökgöz (2018, s. 100) de benzer şekilde halihazırda birçok işletmenin kripto paralar ile satış, ödeme ve tahsilat yaptığını belirterek; kripto paraların "bir yabancı para olarak değerlendirilip işlem tarihindeki kuru üzerinden Türk Lirası'na çevrilerek kayıt altına alınması uygun" olacağı görüşünü savunmuşlardır.

Fakat, Dizkırıcı ve Gökgöz (2018), Ateş’ten (2016) farklı olarak kripto paraların 104 Kripto Paralar Hesab1 veya 108.01 Kripto Paralar Hesab1 isminde bir alt hesapta takip edilmesinin uygun olacağını belirtmişlerdir. Yaptıkları çalışmada ise kripto paraları 108.01 Kripto Paralar Hesabı içerisinde takip etmeyi tercih etmiş̧lerdir. 108 Diğer Hazır Değerler hesabı, hazır değerler grubu içindeki diğer hesaplarda takip edilmeyen vadesi gelmiş kuponlar, pullar, tahsil edilecek banka havaleleri, yoldaki paralar ve kredi kartı ile yapılan satışların izlendiği bir hesaptır. - Dizkırıcı ve Gökgöz'de kripto paraların ulusal para birimine çevrilmesi işleminde veya değerleme işlemlerinde ortaya çıkan kur farklarının 646 Kambiyo Kârları Hesabı veya 656 Kambiyo Zararları Hesabı'nda izlenmesinin uygun olacağını ifade etmişlerdir.

Bu yaklaşıma getirilen eleştirilerin temel kaynağını, kripto paraların, TMS 7'de yapılan "nakit ve nakit benzerleri” tanımlarına uymadığı yönündeki görüş oluşturmaktadır. TMS 7'ye göre nakit, "işletmedeki nakit ile vadesiz mevduatı ifade eder"; nakit benzerleri ise "tutarı belirli bir nakde kolayca çevrilebilen ve değerindeki değişim riski önemsiz olan yüksek likiditeye sahip kısa vadeli yatırımlardır" (Kamu Gözetimi Muhasebe ve Denetim Standartları Kurumu, TMS 7, 2018, s. 1). Tanımda ve standartın devamında geçen "değerindeki değişim riski önemsiz" olan yatırım ve "yatırım amaçlı elde tutulmaması" ifadelerinin kripto paraları nakit veya nakit benzerleri statüsünden çıkardığı savunulmaktadır (Şahin, 2018, s. 913). Gerek kripto paraların yüksek volatil yapısı, gerekse büyük oranda yatırım amaçlı kullanıyor olması bu eleştirilere haklılık payı kazandırmaktadır. Fakat bu eleştiriler kripto paraların mevcut durumuna bağlı olarak yapılmaktadır. Benzer durumlar bazen döviz cinsinden paralarda da görülebilmektedir.

$\mathrm{Bu}$ yaklaşımdaki eksikliklerden bir diğeri de kripto paraların madencilik (mining) sonucunda elde edilmesi durumunda kendini göstermektedir. Kripto para madenciliği kamuya açık bir faaliyettir ve gerekli donanıma sahip herkes bu yöntemle kripto para üretimi yapabilmektedir. Hazır değerler yaklaşımında, kripto para madenciliği sonucu elde edilen kripto varlıkların nasıl aktifleştirileceği, madenciliğin yapıldığ 1 donanımlar ile başta elektrik olmak üzere oluşacak pek çok maliyetin hangi kalemlerde takip edileceği ve değerleme yapılacağı konusunda bir görüş belirtilmemiştir.

\subsection{Kripto Paraların Menkul Kıymetler Hesap Grubu İçinde İzlenmesi}

Kripto varlıkların muhasebeleştirilmesinde öne sürülen yaklaşımlardan biri de bu varlıkların menkul kıymetler hesap grubu içerisinde takip edilmesi yönündedir. Menkul kıymetler hesap grubu, faiz, kâr payı veya fiyat değişimlerinden yararlanılarak kar elde etmek amacıyla geçici (kısa vadeli) olarak alınıp elde tutulan hisse senedi, tahvil, hazine bonosu, finansman bonosu, kâr zarar ortaklığı belgesi gibi finansal varlıkların takip edildiği hesap grubudur.

Menkul kıymetler, ilgili mevzuatlara uygun şekilde çıkartılan ve elinde bulunduranlar için alacak veya ortaklık hakkı doğuran kıymetli evraklardır. Menkul kıymetler hesap grubu içerisinde takip edilen varlıklar başka kişiler tarafından genellikle fon ihtiyacını karşılamak amacıyla çıkarılan; çıkaran için borç, elinde bulunduran için alacak ya da ortaklık hakkı doğuran 
varlıklardır. Menkul kıymetler para değildir fakat para ile temsil edilirler. Tekdüzen hesap planında menkul kıymetler hesap grubu altında hisse senetleri, özel kesim tahvil senet ve bonoları, kamu kesimi tahvil senet ve bonoları ile diğer menkul kıymetler gibi aktif karakterli hesaplar bulunmaktadir.

Yine TMS 32 Finansal Araçlar standardında menkul kıymet türevi ürünler için "bir işletmenin finansal varlığı ile diğer bir işletmenin finansal borcunda ya da öz kaynağa dayalı finansal aracında artş̧a neden olan herhangi bir sözleşmedir" şeklinde bir tanımlama yapılmaktadır (Kamu Gözetimi Muhasebe ve Denetim Standartları Kurumu, TMS 32, 2019, s. 2). TMS 32'ye göre menkul kıymetler, bir işletmenin -genellikle fon ihtiyacını karşılamak amacıyla- finansal borcunun artmasına sebep olan veya öz kaynak yapısını değiştiren sözleşme doğuran belgelerdir.

Gerek tek düzen hesap planı çerçevesinde yapılan tanımlamalar gerekse TMS 32'de yapılan açıklamalar kripto paraların menkul kıymetler olarak izlenmesi yaklaşımını tartışmalı hale getirmektedir. Kripto varlıklar menkul kıymet olarak değerlendirilemez ancak bunların bir araya getirilmesi ile oluşturulacak sepet menkul kıymetleştirilebilir (Yalçın, 2019, s. 108). Kripto paraların sözleşmeye bağlı bir hak veya yükümlülük getirmemekte, herhangi bir işletmenin öz kaynağına bağlı olarak üretilmemekte ve bir işletmeden diğerine geçerken önceki işletme ile bütün bağlantısı sonlanmaktadır (Şahin, 2018, s. 914).

\subsection{Kripto Paraların Stoklar Hesap Grubu İçinde İzlenmesi}

Kripto paraların muhasebeleştirilmesinde ve değerlendirilmesinde önerilen diğer bir yaklaşım da kripto paraların stoklar hesap grubu içinde izlenmesidir. Kripto paraların "Stoklar" hesap grubu içinde izlenmesi yaklaşımını benimseyenlerin temel tezi mevcut düzenlemelerin Bitcoin ve altcoinleri para ya da menkul kıymet olarak kabul etmemesidir. Dolayısıyla kripto paraların bir emtia olarak ele alınıp muhasebeleştirilmesi uygun olacaktır. Kripto paraların emtia olarak değerlendirilmesi Gelir Vergisi, Kurumlar Vergisi ve Katma Değer Vergisi’ni (KDV) de gündeme getirmektedir.

Ateş'e (2017), göre Bitcoin ve altcoinlerin 157 Diğer Stoklar hesabına bağlı bir alt hesapta takip edilmesi uygundur. Ayrıca, kripto paraların gümrüksüz olarak aktife girmesi KDV sorumluluğunu ortadan kaldırmamaktadır. Kripto paralar için vergi sorumlusu sıfatıyla KDV hesaplanmalıdır. Bunların elden çıkarılmasında ise duruma bağlı olarak 600 Yurtiçi Satışlar ya da 601 Yurtdışı Satışlar hesabı ve ilgili KDV hesabı kullanılmalıdır. Envanter işlemi ise 623 Diğer Satışların Maliyeti hesabında takip edilmelidir (Ateş, 2017).

TMS 2 Stoklar standartına göre "stoklar: (a) Olağan iş akışı içinde satılmak üzere elde tutulan, (b) Olağan iş akışı içinde satılmak üzere üretilmekte olan veya (c) Üretim sürecinde veya hizmet sunumunda kullanılacak hammadde ve malzeme şeklinde bulunan varlıklardır" (Kamu Gözetimi Muhasebe ve Denetim Standartları Kurumu, TMS 2, 2018, s. 1). Kripto paraların bazılarının üretilememesi, bazılarının sınırlı sayıda üretilebilmesi, her hangi bir ürün veya hizmetin ilk madde malzemesi olamayacağ 1 düşüncesi; kripto para birimlerini kullanan işletmelerin çoğunun faaliyet alanının kripto para ticareti olmaması, kripto para birimlerinin değerlemesi ve gerçek değerinin hesaplanmasının zorluğu kripto paraların stoklar hesap grubu içinde muhasebeleştirmesi yaklaşımının eksikliklerini göstermektedir (Şahin, 2018, s. 913-914).

Ayrıca, kripto paraların, "stoklar gibi parasal olmayan varlıkların” (Kamu Gözetimi Muhasebe ve Denetim Standartları Kurumu, TMS 1, 2018, s. 12) takip edildiği bir hesap grup içerisinde takip edilmesi, yaklaşımı tartışmalı hale getirmektedir. Buna ek olarak, KDV kanunu 1. Maddesine göre; (i) Ticari, sınai, zirai faaliyet ve serbest meslek faaliyeti çerçevesinde yapılan teslim ve hizmetler, (ii) Her türlü mal ve hizmet ithalatı, (iii) diğer faaliyetlerden doğan teslim ve hizmetler katma değer vergisine tabidir (Katma Değer Vergisi Kanunu, 1984). Dolayısıyla stoklar hesap gurubu içindeki malların teslimi KDV'nin konusunu oluşturmaktadır. Kripto paraların yüksek likiditeye sahip fiziki varlıklar olması ve mevcut vergilendirmeye 
ilişkin düzenlemelere uymaması, onların, stoklar hesap grubunda takip edilmesi yaklaşımını zayıflatmaktadır.

\subsection{Kripto Paraların Maddi Olmayan Duran Varlıklar Hesap Grubu İçinde İzlenmesi}

Kripto paraların muhasebeleştirilmesinde önerilen temel yaklaşımlardan dördüncüsü de onların maddi olmayan duran varlıklar sınıfında ele alınmasıdır. Şahin'e (2018) göre TMS 38 Maddi Olmayan Duran Varlıklar standardında geçen tanımlar kripto paraları kapsamaktadır. Ona göre bir varlık olarak kripto paralar, -standartta belirtilen-, gelecekte fayda sağlamalarının beklenebilmesi ve belirlenebilirlik kriterini karşılayabildikleri için maddi olmayan duran varlık sınıflandırılması içinde ele alınmalıdırlar. Kripto paralar muhasebeleştirilirken maliyet bedeli esas alınmalı, dönem sonunda yeniden değerlemeye tabi tutulmalı, yeniden değerleme sonucunda ortaya çıkabilecek artış veya azalışlar diğer kapsamlı gelirde muhasebeleştirilerek öz kaynakta biriktirilmelidir. Ayrıca kripto paraların amortismana tabi tutulmasına gerek yoktur (Şahin, 2018, s. 915-916). Şahin (2018), kripto paraların, maddi olmayan duran varlıklar grubu içerisinde hangi hesapta takip edilmesi gerektiğine ilişkin bir görüş belirtmemiştir.

TMS 38 Maddi Olmayan Duran Varlıklar standardında göre bir maddi olmayan duran varlığın bu sınıflandırma içinde muhasebeleştirilebilmesi için "belirlenebilirlik, bir kaynak üzerindeki kontrol ve gelecekteki ekonomik yararının varlığı gibi" unsurları karşılaması gerekmektedir. Kripto paraların bu özellikleri karşıladıkları söylenebilir. Ayrıca standart açıklanırken bilgisayar yazılımı ve programları gibi sanal karakterli ürünlere de atıf yapılmaktadır.

Fakat TMS 38'e göre bir maddi olmayan duran varlık: "Fiziksel niteliği olmayan tanımlanabilir parasal olmayan varlıktır". Parasal varlıklar ise: "Elde tutulan para ile sabit ya da belirlenebilir tutarda bir para cinsinden elde edilecek varlıklardır". Yine TMS 38'e göre "Maddi olmayan duran varlığın niteliği gereği, birçok durumda, ilgili varlığa herhangi bir ekleme veya bir parçasında yenileme olmaz." (Kamu Gözetimi Muhasebe ve Denetim Standartları Kurumu, TMS 38, 2018).

Oysa kripto varlıklar belirlenebilir tutarda bir para cinsinden kripto para borsalarında alınıp satılabilmekte, hatta artan oranda ticarete konu olmaktadır. Ayrıca kripto paralara istenildiği anda ekleme ve daha da önemlisi, çıkarma yapılabilmektedir. Maddi olmayan duran varlıklar, yapıları itibariyle kolaylıkla bölünerek satılabilecek nitelikte değillerdir. Dolayısıyla kripto paraların maddi olmayan duran varlıklar hesap grubu içerisinde muhasebeleştirilmesi yaklaşımı da birtakım belirsizlikler yaratmakta ve yaklaşımı zayıflatmaktadır.

\section{Tartışma}

Kripto paralar daha önce varlık olarak sınıflandırdığımız şeylere benzememektedir. Buna rağmen Bitcoin ve türevi kripto paralar on yılı aşkın bir süredir hayatımızdadır ve her geçen gün daha fazla ticari işleme konu olmaktadır. Dolayısıyla bir varlık çeşidi olan kripto paralar ile yapılan ticari işlemlerin muhasebeleştirilmeleri gerekmektedir. Henüz kripto paralar ile yapılan ticari işlemlerin muhasebeleştirilmelerine ilişkin belirgin bir düzenleme olmaması konuya farklı yaklaşımların getirilmesine sebep olmaktadır.

$\mathrm{Bu}$ çalışmada kripto varlıkların muhasebeleştirilmesinde ön plana çıkan dört yaklaşım tartışılmıştır. Bunlardan ilki kripto varlıkların hazır değerler grubu içerisinde takip edilmesi görüşünü savunmaktadır. Fakat Avrupa Merkez Bankasının kripto paraların nakit ya da döviz sayılamayacağı yönündeki kararı ve -bilindiği kadarıyla- kripto paraların -henüz- herhangi bir merkez bankası envanterine girmemiş olması kripto varlıkların nakit para olarak değerlendirilmesi fikrini tartışmalı hale getirmektedir.

Kripto varlıkların muhasebeleştirilmesindeki bir diğer yaklaşımsa onları menkul kıymet olarak ele almak yönündedir. Fakat gerek tek düzen hesap planında çizilen çerçeve gerekse TMS 32'deki açıklamalar kripto varlıkların menkul kıymetler olarak izlenmesi yaklaşımının 
sakıncalarını oluşturmaktadır. Çünkü kripto varlıkları edinmek -menkul kıymetlerde olduğu gibi- elinde bulunduranlar için bir alacak veya ortaklık hakkı doğurmazken, ihraç edenler için de bir borç veya öz kaynak değişimi yaratmamaktadır.

Bir başka yaklaşımsa kripto varlıkların stoklar hesap grubu içerisinde izlenmesin savunmaktadır. Fakat TMS 2'de yapılan tanımlardan da anlaşılacağı üzere stoklar maddi (fiziki) nitelikte varlıklardır. Stoklar, ilk madde ve malzeme, yarı mamul, mamul, ticari mal, yan ürün, artık ve hurda gibi somut varlıklardan oluşmaktadır. Kripto varlıkların dijital yapıda olması onları muhasebe standartlarına uygun stoklar grubu alt hesaplarına dahil edilmesini tartışmalı hale getirmektedir. Ayrıca stok kalemlerinin elde edilmesi ve satılması KDV, ÖTV gibi vergi yükümlülükleri de getirmektedir. Mevzuatta bu konuda bir kesinlik bulunmamaktadır.

Kripto varlıkların muhasebeleştirilmesinde ön plana çıkan dördüncü yaklaşımsa onların maddi olamayan duran varlık sinıflamasına sokulması yönündedir. Kripto varlıkların belirlenebilir tutarda bir para cinsinden kripto para borsalarında alınıp satılabilmesi, artan oranda ticarete konu olması, istenildiği anda ekleme ve çıkarma yapılabilmesi bu yaklaşımda birtakım belirsizlikler yaratmakta ve yaklaşımı zayıflatmaktadır. Oysa maddi olmayan duran varlıklar, yapıları itibariyle kolaylıkla bölünerek satılamamaktadırlar.

\section{Sonuç ve Öneriler}

Kripto paraların bir varlık sınıfı olarak muhasebe bilgi sistemi içinde nasıl kayıt altına alınabileceğini değerlendirmek amacıyla yapılan bu çalışmada literatürdeki belli başlı dört yaklaşım ele alınarak tartışılmıştır. Bunlar, kripto varlıkların, hazır değerler hesap grubu içerisinde izlenmesini yaklaşımı, menkul kıymet hesap grubu içerisinde izlenmesi yaklaşımı, stoklar hesap grubu içerisinde izlenmesi yaklaşımı ve maddi olmayan duran varlıklar hesap grubu içerisinde izlenmesi yaklaşımıdır. Bu yaklaşımların her birinin çeşitli argümanları buna karşılık çeşitli zayıflıkları da bulunmaktadır.

Bizce değerlendirilen bu yaklaşımlar içerisinde -diğer yaklaşımlardaki gibi birtakım eksikleri olmasına rağmen- en uygun olanı kripto varlıkların para olarak ele alındığı hazır değerler yaklaşımıdır. Çünkü kripto varlıkların paranın fonksiyonları olan değişim aracı olma, değer saklama aracı olma, hesap birimi olma ve gelecekteki ödemeler için bir ölçüt olma özelliklerine yakınsayan yönleri bulunmaktadır. Ayrıca kripto varlıklar son derece likit varlıklardır ve kripto para olgusunu günümüze taşıyan makalenin yazarı Nakamoto da bu varlıkları para (the coin) olarak ifade etmiştir. Kripto paraların muhasebeleştirilmesine ilişkin tartışmalar ilgili düzenlemelerin yapılmasına kadar devam edecek gibi görünmektedir.

\section{Kaynakça}

Akleylek, S., Yıldırım H. M. ve Tok, Z. Y. (2011). Kriptoloji ve uygulama alanları: açık anahtar altyapısı ve kayıtlı elektronik posta. Akademik Bilişim'11 - XIII. Akademik Bilişim Konferansı Bildirileri, 2-4 Şubat 2011 İnönü Üniversitesi, Malatya, Erişim adresi: https://ab.org.tr/ab11/kitap/akleylek_yildirim_AB11.pdf

Ateş, B. A. (2016). Kripto para birimleri, Bitcoin ve muhasebesi. Çankır Karatekin Üniversitesi Sosyal Bilimler Enstitüsü Dergisi, 7(1), 349-366.

Ateş, K. (2017). Bitcoin işlemlerinin muhasebe kayıtları. http://www.muhasebetr.com/yazarlarimiz/koray/0254/ (Erişim tarihi:10.09.2018).

Avrupa Merkez Bankası (2015). Virtual currency schemes - a further analysis. https://www.ecb.europa.eu/pub/pdf/other/virtualcurrencyschemesen.pdf (Erişim tarihi: 04.09.2018).

Bankacılık Düzenleme ve Denetleme Kurumu. (2013). Basın açıklaması. Sayı: 2013/32. 
Chokun, J. (2018). Who accepts Bitcoins as payment? List of companies, stores, shops. https://99bitcoins.com/who-accepts-bitcoins-payment-companies-stores-take-bitcoins/ (Erişim tarihi: 18.09.2018).

Coşkun, A. ve Ülker, Ü. (2013). Ulusal bilgi güvenliğine yönelik bir kriptografi algoritması geliştirilmesi ve harf frekans analizine karşı güvenirlik tespiti. Biliş̧im Teknolojileri Dergisi, 6(2), 31-39.

Cryptocurrency explained. https://college.lbx.com/basics/0-cryptocurrency-explained/ (Erişim tarihi: 21.08.2018).

Dizkırıc1, A. S. ve Gökgöz, A. (2018). "Kripto para birimleri ve Türkiye'de Bitcoin muhasebesi. Journal of Accounting, Finance and Auditing Studies, 4(2), 92-105.

Fico, P. (2018). Virtual currencies and blockchains: potential impacts on financial market infrastructures and on corporate ownership. https://mbs.edu/getattachment/fircg/FIRCG2016/Papers/7-Paola-Fico_-virtual-currency-blockchain-mb.pdf (Erişim tarihi: 04.09.2018)

Gelir İdaresi Başkanlığı. (2018). G. Geçici Maddelerde Yer Alan İstisnalar. http://www.gib.gov.tr/fileadmin/mevzuatek/kdvgeneluygulamatebligi/kdvgeneluygulamatebl igi_2g.htm (Erişim tarihi: 10.09.2018).

Gültekin, Y. (2017). Turizm endüstrisinde alternatif bir ödeme aracı olarak kripto para birimleri: Bitcoin”, Güncel Turizm Araştırmaları Dergisi, 1(2), 96-113.

Harrison, J. \& Mano, R. (2015). Accounting for virtual currency transactions. Journal of the Utah Academy of Sciences, Arts \& Letters, 92, 109-118.

Herdman, E. A. (2006). Derleme makale yazımında, konferans ve bildiri sunumu hazırlamada pratik bilgiler. (Z. Dörtbudak, Çev.). Hemşirelikte Eğitim ve Araştırma Dergisi, 3(1), 2-4.

Kamu Gözetimi Muhasebe ve Denetim Standartları Kurumu. (2018). Finansal raporlamaya ilişkin kavramsal çerçeve. http://www.kgk.gov.tr/Portalv2Uploads/files/DynamicContent Files/T\%C3\%BCrkiye\%20Muhasebe\%20Standartlar\%C4\%B1/TMSTFRS2018Seti/Finansal \%20Raporlamaya\%20\%C4\%B0li\%C5\%9Fkin\%20Kavramsal\%20\%C3\%87er\%C3\%A7eve/ K\%C3\%87_2018.pdf (Erişim tarihi: 13.09.2018).

Kamu Gözetimi Muhasebe ve Denetim Standartları Kurumu. (2018). TMS1, TMSlfinansal tablolarin

http://kgk.gov.tr/Portalv2Uploads/files/Duyurular/v2/TMS/TMS\%202\%20Stoklar.pdf (Erişim tarihi: 14.09.2018).

Kamu Gözetimi Muhasebe ve Denetim Standartları Kurumu. (2018). TMS 2, stoklar. http://kgk.gov.tr/Portalv2Uploads/files/Duyurular/v2/TMS/TMS\%202\%20Stoklar.pdf (Erişim tarihi: 14.09.2018).

Kamu Gözetimi Muhasebe ve Denetim Standartları Kurumu. (2018). TMS 7, nakit akış tablolart.

https://www.kgk.gov.tr/Portalv2Uploads/files/DynamicContentFiles/T\%C3\%BCrkiye\%20M uhasebe\%20Standartlar\%C4\%B1/TMSTFRS2019Seti/TMS/TMS\%207.pdf (Erişim tarihi: 07.09.2019).

Kamu Gözetimi Muhasebe ve Denetim Standartları Kurumu. (2019). TMS 32, finansal araçlar: Sunum. https://www.kgk.gov.tr/Portalv2Uploads/files/DynamicContentFiles/T\%C3\%BCrkiye\%20M uhasebe\%20Standartlar\%C4\%B1/TMSTFRS2019Seti/TMS/TMS\%2032.pdf

Katma Değer Vergisi Kanunu, Kanun No: 3065, 2 Kasım 1984 ve 18563 sayılı Resmi Gazete. 
Koçoğlu, Ş., Çevik, Y. E., ve Tanrı̈ven, C. (2016). Bitcoin piyasalarının etkinliği, likiditesi ve oynaklığı. İşletme Araştırmaları Dergisi, 8(2), 77-97.

Köse, B. (2018, Nisan). G20 toplantılarında Bitcoin'le ilgili öne çıkan 10 düşünce. https://uzmancoin.com/bitcoin-g20-dusunce/ (Erişim tarihi: 12.09.2018).

Nakamoto, S. (2008). "Bitcoin: A peer-to-peer electronic cash system", https://bitcoin.org/bitcoin.pdf (Erişim tarihi: 04.08.2018).

Ödeme ve Menkul Kiymet Mutabakat Sistemleri, Ödeme Hizmetleri ve Elektronik Para Kuruluşları Hakkında Kanun (2013, 27 Haziran). Resmi Gazete (Say1: 28690). http://www.mevzuat.gov.tr/MevzuatMetin/1.5.6493.pdf (Erişim tarihi: 13.09.2018).

Review (Derleme) Makale Nedir? Nasıl Yazılır?. (2018, 7 Kasım). Erişim adresi: https://www. evrakisleri .net/2018/11/07/review-derleme-makale-nedir-nasil-yazilir/

Şahin, O. N. (2018). TMS \& TFRS işiğinda muhasebe, vergi ve denetim açisindan Bitcoin ve diğer kripto para birimleri. Muhasebe Bilim Dünyası Dergisi, 20(4), 898-923.

Türken, S. (2018, Mart). G20 Finansal istikrar kurulu Bitcoin ve diğer kripto para birimlerinin düzenlenmesi taleplerini reddetti, https://koinbulteni.com/g20-finansal-istikrar-kurulu-kriptopara-birimlerinin-duzenlenmesi-taleplerini-reddetti-10337.html (Erişim tarihi: 16.09.2018).

Yalçın, S. (2019). Kripto değişim araçlarının muhasebeleştirilmesi. Muhasebe ve Finansman Dergisi, 81: 101-120.

Yüksel, A. E. B. (2015). Elektronik para, sanal para, Bitcoin ve Linden Doları'na hukuki bir bakış. İstanbul Üniversitesi Hukuk Fakültesi Mecmuası, 2, 173-220.

\section{ETIKK ve BİLIMSEL İLKELER SORUMLULUK BEYANI}

$\mathrm{Bu}$ çalışmanın tüm hazırlanma süreçlerinde etik kurallara ve bilimsel atıf gösterme ilkelerine riayet edildiğini yazar(lar) beyan eder. Aksi bir durumun tespiti halinde Afyon Kocatepe Üniversitesi Sosyal Bilimler Dergisi'nin hiçbir sorumluluğu olmayıp, tüm sorumluluk makale yazarlarına aittir. 